\title{
Life in the Balance: Young Female Sex Workers in Kenya Weigh the Risks of COVID-19 and HIV
}

\author{
Joanne E. Mantell ${ }^{1}$ - Julie Franks ${ }^{2} \cdot$ Maria Lahuerta $^{2} \cdot$ Dan Omollo $^{3} \cdot$ Allison Zerbe $^{2} \cdot$ Mark Hawken $^{2} \cdot$ Yingfeng Wu $^{2}$. \\ Doris Odera ${ }^{2} \cdot$ Wafaa M. El-Sadr ${ }^{2} \cdot{\mathrm{Kawango} \text { Agot }^{3}}^{3}$
}

Accepted: 14 December 2020 / Published online: 2 January 2021

(c) The Author(s), under exclusive licence to Springer Science+Business Media, LLC part of Springer Nature 2021

\begin{abstract}
The COVID-19 pandemic has had serious health, economic and psychosocial consequences. Marginalized populations including female sex workers face the stark choice of risking exposure to SARS-CoV-2 as they engage with clients or prioritizing their health at the cost of losing a primary source of income. As part of an ongoing open-label, randomized controlled trial providing daily oral pre-exposure prophylaxis and adherence support, we interviewed 193 of 200 enrolled young female sex workers (18-24 years) in Kisumu, Kenya, about COVID-19 awareness and precautions, access to health services, and sex work during Kenya's pandemic-related lockdown. Nearly all participants were aware of COVID-19 and reported taking protective measures, but only half reported concerns about acquiring SARS-CoV-2. Night curfews and bar closures adversely affected participants' sex work business, reducing the number of clients and payment amounts from clients. Nearly $15 \%$ experienced violence from a client or regular, non-paying sex partner during the lockdown period. Participants' access to healthcare services was not disrupted.
\end{abstract}

Keywords COVID-19 $\cdot$ SARS-CoV-2 $\cdot$ Kenya $\cdot$ Female sex workers $\cdot$ Pre-exposure prophylaxis

\section{Resumen}

La pandemia de COVID-19 puede tener graves consecuencias sanitarias, económicas y psicosociales. Poblaciones marginadas como las mujeres trabajadoras sexuales se enfrentan a la dura elección de arriesgarse a exponerse al SARS-CoV-2 mientras interactúan con los clientes o priorizar su salud a riesgo de perder su principal fuente de ingresos. Como parte de un ensayo controlado aleatorio abierto en curso que proporcionaba profilaxis pre-exposición (PrEP) oral diaria y apoyo para la adherencia, entrevistamos a 193 de 200 las mujeres trabajadoras sexuales jóvenes (de 18 a 24 años) en Kisumu, Kenia, sobre su conocimiento y precauciones frente al COVID-19, acceso a servicios de salud, y trabajo sexual durante el confinamiento por la pandemia en Kenia. Casi todas las participantes conocían el COVID-19 y reportaron que tomaron medidas de protección, pero sólo la mitad dijeron estar preocupadas por infectarse con el SARS-CoV-2. Los toques de queda nocturnos y los

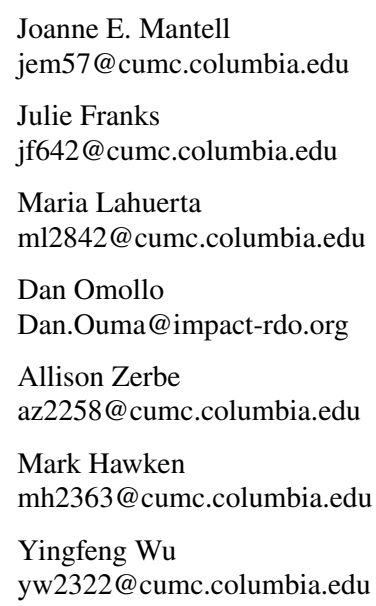

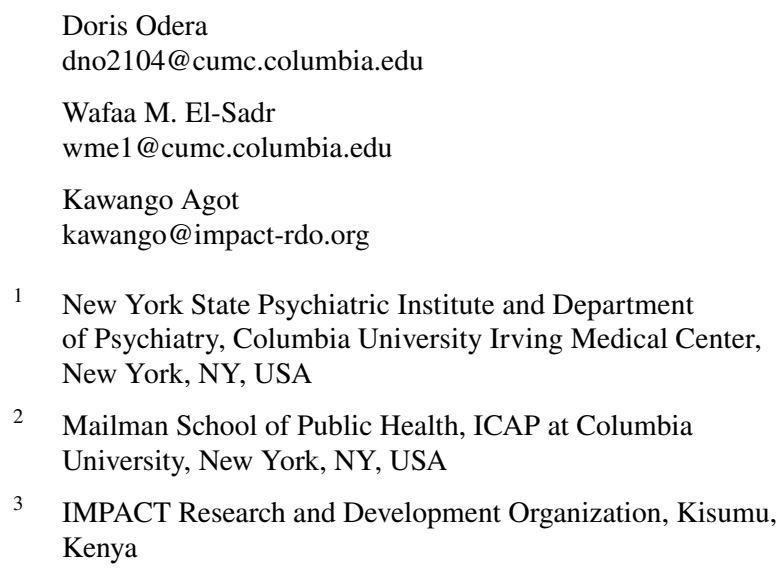


cierres de bares afectaron negativamente al negocio del trabajo sexual, reduciendo el número de clientes y la cantidad que recibieron de los clientes. Casi el 15\% experimentó violencia por parte de un cliente o por una pareja sexual habitual que no paga durante el periodo de confinamiento. El acceso de las participantes a los servicios de salud no se vio interrumpido.

\section{Introduction}

The COVID-19 pandemic and national responses to it have had serious health, economic and psychosocial consequences [1-3]. Vulnerable and marginalized populations such as female sex workers face the stark choice of risking exposure to SARS-CoV-2 as they engage with clients or prioritizing their health at the cost of losing a primary source of income. In March 2020, the Kenyan government enacted broad measures to prevent the spread of SARS-CoV-2 infection, referred to as a lockdown. Measures included strict limits on national travel; a dawn-to-dusk curfew; and closure of clubs, bars, and other public venues. These measures curtailed the ability of female sex workers to engage in street-based sex work [4], compounding the omnipresent threat of arrest for sex work with detention for curfew violation. The number of confirmed COVID-19 cases in Kenya rose slowly between March and May 2020 but the rate of increase picked up between June and October 2020, and at the end of September 2020, the national government reintroduced mitigation measures to curb the spread of COVID-19. Kenya's SARS-CoV-2 testing capacity has grown throughout 2020 , with a weekly testing rate of 6000 per day the week of November 9, 2020 [5].

As of December 22, 2020, there were 94,614 COVID-19 cases in Kenya, the second highest number of confirmed cases among East African nations after Ethiopia (120,348 cases) $[6,7]$. Documentation of the pandemic's impact on the dynamics of sex work, female sex workers' socio-economic livelihoods, and their access to HIV services has been limited. We evaluated the effects of the COVID-19 pandemic in early 2020 among a cohort of young female sex workers aged 18-24 years enrolled in an ongoing HIV pre-exposure prophylaxis (PrEP) study in Kisumu, Kenya.

\section{Methods}

\section{Study Design and Eligibility Criteria}

We enrolled and conducted baseline interviews with 200 young (18-24 years old) female sex workers in the IPrEP study in Kisumu, Kenya, between October 2019 and February 2020. IPrEP is an ongoing open-label, randomized controlled trial providing daily oral pre-exposure prophylaxis (PrEP) for HIV prevention to young female sex workers and comparing the effectiveness, feasibility, and acceptability of two behavioral support interventions to optimize PrEP adherence. Participants will be followed for 24 months. Criteria for trial participation are: (1) no previous diagnosis of HIV infection; (2) being a biological female; (3) age 18-24 years; (4) living or working in study area; (5) intention to stay in study area for 24 months; (6) exchange sex with men for goods, money, favors or other services in past 3 months; (7) no current or recent (within past 3 months) PrEP use; (8) able to complete study procedures in English, Kiswahili or Dholuo; and (9) willingness to be randomized and adhere to PrEP plus adherence support interventions.

\section{Study Setting}

Study participants were recruited through community outreach and social network referrals in the greater Kisumu area. Kenya's third-largest city, Kisumu, has been proactive in increasing community COVID-19 awareness and protection measures. It operates a successful fully digitized COVID-19 Response Call Centre at Maseno University; has trained healthcare providers and community health workers on the management of COVID-19 patients on home-based care; sensitized security personnel and the police [8]; and advocated for handwashing [9]. There are two public-sector COVID-19 testing facilities in Kisumu; however, a shortage of reagents has caused delays in conducting the tests. As a result, samples had to be transported to Nairobi and testing restricted to those who present themselves at hospitals and their close contacts $[10,11]$. This has constrained the number of tests performed daily [12]. The number of COVID-19 tests performed in Kisumu has increased from 350 between April-August 2020 to 1138 between Sept 20th to Nov 12th, 2020. The percent of positive tests increased from 2\% between April-August 2020 to $11.5 \%$ in the period from Sept 20th to Nov 12th, 2020 [13].

\section{Measures}

A brief module of questions focused on COVID-19 awareness and precautions, access to health services, and sex work during Kenya's COVID-19 state of emergency was integrated into study follow-up visit interviews. Specifically, we asked participants about the effects of COVID-19 on their income, access to food, sex work (number of clients, interactions with clients, venues for meeting and having sex with clients, amount of money charged clients), ability to obtain needed health care services, ability to obtain PrEP medication from the study, and violence from a client or regular/main sexual partner. We also asked about whether 
participants experienced an increase or decrease in stigma or discrimination (i.e., how people treat them because they are sex workers), concerns about getting infected with COVID19 , and measures for self-protection.

\section{Procedures}

At scheduled 3- and 6-month follow-up visits between April and July 2020, participants were given a three-month supply of PrEP medication and an oral OraQuick In-Home HIV Test (HIV self-test; HIVST) kit [14] to support PrEP use during the lockdown. Participants received an orientation to the HIVST and reviewed instructions for use with the study staff. They were asked to send the study staff a photo or text of their HIVST results. We did not provide incentives to study participants for using the HIV self-test kits and returning their test results. Research assistants working remotely conducted participant follow-up interviews, including the COVID-19 module by telephone, to maintain physical distancing. Participants received protocol-specified compensation in Kenyan shillings equivalent to $\$ 5$ for scheduled follow-up interviews.

\section{Ethical Considerations}

The study was approved by the Maseno University Ethics Review Committee and the Columbia University Irving Medical Center Institutional Review Board. All study participants provided written informed consent at enrollment in the main study. Modifications to study procedures to maintain physical distancing were approved by the two ethics bodies; participants provided verbal consent to telephone interviews.

\section{Analysis}

For participants with both 3- and 6-month interviews during the period of COVID-19-specific data collection, only 3-month data were used in the analysis. Baseline and followup interview responses were analyzed using descriptive statistical methods in SAS v 9.4 (Cary, NC).

\section{Results}

A total of 193 of 200 (96.5\%) enrolled study participants completed the COVID-19 survey module during scheduled study follow-up interviews. The primary reason for nonparticipation of seven women in the follow-up interviews was that the participant could not be reached by phone.

\section{Baseline Characteristics of Participants}

Table 1 describes the baseline, pre-pandemic sociodemographic characteristics of those IPrEP study participants completing the COVID-19 questions. The median age was 22 years $(\mathrm{IQR}=20-23)$. More than one-third $(38.9 \%)$ completed secondary education or higher, $70.5 \%$ were not married and not living with a partner, and over a quarter (26.9\%) had no regular partner.

More than three-quarters (78.2\%) lived in an informal settlement or other urban neighborhoods in Kisumu. Most had electricity at home (71.0\%), 25.4\% had a refrigerator, $47.7 \%$ a television, $87.1 \%$ a mobile phone and $9.3 \%$ an indoor toilet. Regarding living arrangements, $21.8 \%$ lived alone, $35.2 \%$ with relatives, $24.9 \%$ with their children, $29.5 \% \%$ with a roommate or other paying residents, and only $1.6 \%$ with a partner. Forty-four percent of participants reported not having enough money for essentials and another $45.1 \%$ indicated that although money to buy food was adequate, they had limited funds for other things. Only $10.4 \%$ of all participants reported having sufficient funds for their household needs. Two-fifths (40.9\%) supplemented sex work income with additional work, such as informal sales, domestic labor, and other income-generating sources.

The median number of paying sex partners in the last month was 12 (IQR: 5-37), with $78.2 \%$ reporting condom use at last sex with a paying partner. The most common venues where sex workers engaged clients were bars, clubs, and other entertainment venues (78.8\%), followed by telephone (39.4\%) and roadsides/streets (22.3\%) (Table 2). The most frequently reported venues for having paid sex were rented rooms in a lodging or bar (89.6\%) and the client's home $(20.2 \%)$.

\section{Effects of the COVID-19 Pandemic}

Nearly all (99.0\%) study participants were aware of COVID19 and reported taking protective measures, including wearing face masks (80.1\%), frequent hand washing $(69.1 \%)$, using hand sanitizer (39.8\%), and staying at home more $(30.9 \%)$ (see Table 3). Over half $(52.9 \%)$ were somewhat or very concerned about becoming infected with SARS-CoV-2 virus.

In response to the question of whether the COVID-19 state of emergency affected their ability to get any needed health services, a majority of participants $(82.9 \%)$ reported that COVID-19 did not affect their ability to obtain health services. Nearly all $(91.2 \%)$ indicated that they had no problem getting their PrEP medications from the study site. Among the minority who reported difficulty getting PrEP medications, traveling to pick up the medication and having moved out of the study area were the two most common reasons cited. 
Table 1 Baseline preCOVID-19 background characteristics of participants completing COVID-19 survey $(\mathrm{N}=193)$

\begin{tabular}{|c|c|c|}
\hline & $\mathrm{n}$ & $\% *$ \\
\hline Age (median, interquartile range) & & $22(20-23)$ \\
\hline Completed secondary or higher & 75 & 38.9 \\
\hline \multicolumn{3}{|l|}{ Current marital status } \\
\hline Legally married, not living with her partner & 2 & 1.0 \\
\hline Not married, and living with her partner & 3 & 1.6 \\
\hline Not married and not living with her partner & 136 & 70.5 \\
\hline Has no partner & 52 & 26.9 \\
\hline Living in urban area, informal settlement & 151 & 78.2 \\
\hline \multicolumn{3}{|l|}{ Socioeconomic status, have the following at home: } \\
\hline Electricity inside & 137 & 71.0 \\
\hline Refrigerator & 49 & 25.4 \\
\hline Television & 92 & 47.7 \\
\hline Mobile phone & 168 & 87.1 \\
\hline Indoor toilet & 18 & 9.3 \\
\hline \multicolumn{3}{|l|}{ Currently living with } \\
\hline Alone & 42 & 21.8 \\
\hline Own children & 48 & 24.9 \\
\hline Relatives & 68 & 35.2 \\
\hline Partner(s) & 3 & 1.6 \\
\hline Roommate(s) and other paying residents & 57 & 29.5 \\
\hline \multicolumn{3}{|l|}{ Household economic situation } \\
\hline Not enough money & 85 & 44.0 \\
\hline Money for food but short on many things & 87 & 45.1 \\
\hline Have enough money for most important things & 20 & 10.4 \\
\hline Have some extra money & 1 & 0.5 \\
\hline Received money for work other than sex work in the past month & 79 & 40.9 \\
\hline \multicolumn{3}{|l|}{ Type of work conducted in past month other than sex work $(n=79)$} \\
\hline Informal sales (e.g. fruit, vegetables, flowers) & 13 & 16.5 \\
\hline Domestic work/housekeeper & 11 & 13.9 \\
\hline Other income-generating sources & 47 & 59.5 \\
\hline Catering & 8 & 10.1 \\
\hline Shopkeeper & 2 & 2.5 \\
\hline
\end{tabular}

*Unless indicated otherwise
When asked how others treated them during the lockdown, $17.1 \%$ of participants noted an increase in stigma or discrimination against sex workers and $14.5 \%$ experienced violence from a client or regular non-paying sex partner during the lockdown.

Most participants (92.2\%) reported a reduction in access to basic needs and $79.3 \%$ reported lower payments from clients. When asked how COVID-19 affected their work, 85.0\% indicated that the pandemic changed their work with clients: 83.9\% reported fewer clients seeking sex and using different meeting and sex locations ( $72.5 \%$ and $73.1 \%$, respectively).

Of the 187 participants who were given HIVST kits as a way to screen for their HIV status prior to using a new bottle of PrEP medication, 97.3\% $(n=182)$ reported their results to study staff - 143 sent a photo of test result via phone, 38 via short message service (SMS), and one called for support to read her result. (These program data are not shown in a table) Of the remaining five participants, two physically brought the HIVST kit results to the study facility, one verbally reported her results on the date of her study follow-up visit, and another two reported having lost their kits, but were tested at the facility on their study follow-up visit date. The remaining six participants did not come to the study site to receive HIVST kits but were tested at the study facility when face-to-face study activities resumed. No positive test results were reported.

\section{Discussion}

Our findings highlight the dilemma that women engaged in sex work face in balancing how to protect themselves from the risk of exposure to the SARS-CoV-2 virus while 
Table 2 Baseline sex work characteristics $(\mathrm{N}=193)$

\begin{tabular}{|c|c|c|}
\hline & \multicolumn{2}{|c|}{ Baseline } \\
\hline & $\mathrm{N}$ & $\% *$ \\
\hline Conducted sex work in a community outside of Kisumu in past year & 42 & 21.8 \\
\hline Age of sexual debut (median, $I Q R$ ) & & $16(15-17)$ \\
\hline $\begin{array}{l}\text { No. of sex partners with whom they had sex in exchange for money in past } \\
\text { month, (median, } I Q R \text { ) }\end{array}$ & & $12(5-37)$ \\
\hline Condom use at last sex with last paid partner & 151 & 78.2 \\
\hline No. of regular non-paying sex partners in past month (median, $I Q R$ ) & & $1(1-2)$ \\
\hline Condom used at last sex with last regular non-paying sex partner & 75 & 50.7 \\
\hline \multicolumn{3}{|l|}{ Where commonly meet sex work clients (pre-pandemic) } \\
\hline Bar/club/entertainment center & 152 & 78.8 \\
\hline Telephoned by client & 76 & 39.4 \\
\hline Roadside/street & 43 & 22.3 \\
\hline Hotel & 26 & 13.5 \\
\hline Home & 12 & 6.2 \\
\hline Brothel & 9 & 4.7 \\
\hline Other & 10 & 5.2 \\
\hline No answer & 1 & 0.5 \\
\hline \multicolumn{3}{|l|}{ Where commonly have sex with clients (pre-pandemic) } \\
\hline Rented room in lodging or bar & 173 & 89.6 \\
\hline Client's home & 39 & 20.2 \\
\hline Brothel & 13 & 6.7 \\
\hline My home & 14 & 7.3 \\
\hline In the bush/outside & 3 & 1.6 \\
\hline Car/lorry/trailer parking zone & 3 & 1.6 \\
\hline Other & 4 & 2.1 \\
\hline \multicolumn{3}{|l|}{ Chances of getting HIV } \\
\hline No risk at all & 23 & 11.9 \\
\hline Small & 18 & 9.3 \\
\hline Moderate & 90 & 46.6 \\
\hline Great & 62 & 32.1 \\
\hline Ever used an HIV self-test kit & 34 & 17.7 \\
\hline
\end{tabular}

*Unless indicated otherwise maintaining their economic livelihoods. In the first four months following Kenya's enforcement of restrictions to mitigate COVID-19 transmission, only about half of female sex workers in our study reported concerns about acquiring the virus. Night curfews and closure of bars and clubs adversely affected female sex workers' sex work business, reducing the number of clients and the amount of payment from clients who also may have had less money to spend. One female sex worker interviewed on a popular news website commented: "many of our clients have also lost jobs, so as long as they are jobless, we are also jobless" [15]. Such restrictions also may compel female sex workers to abandon precautionary infection prevention measures so that they can continue earning an income [16]. Although there is no evidence of sexual transmission of COVID-19, sex work entails close contact between sex workers and clients that creates an opportunity for respiratory droplet transmission.

Even before the COVID-19 lockdown, the financial security of this cohort of young female sex workers was precarious, with a substantial number reporting they did not have enough money and needing to supplement their sex work income with other income-generating activities. However, economic vulnerability increased during COVID-19 lockdown due to fewer clients and reduced income from sex work. Common venues for meeting clients and having sex became less accessible at the same time as other opportunities for income-generating work such as small-scale sales and catering suffered under the lockdown.

Within the several weeks of lockdown prior to being interviewed, $14.5 \%$ of participants had experienced gender-based violence from a client or regular non-paying sex partner. This finding is consistent with other reports 
Table 3 Effects of COVID-19 restrictions on participants $(\mathrm{N}=193)$

\begin{tabular}{|c|c|c|}
\hline & $\mathrm{N}$ & $\%$ \\
\hline Heard of COVID-19 & 191 & 99.0 \\
\hline \multicolumn{3}{|l|}{ Taking special measures to protect yourself from getting infected with COVID-19 } \\
\hline Yes & 191 & 99.0 \\
\hline Using face mask more often & 153 & 80.1 \\
\hline Washing hands more often using soap and (running) water & 132 & 69.1 \\
\hline Disinfecting hands using hand sanitizer & 76 & 39.8 \\
\hline Staying at home more & 59 & 30.9 \\
\hline Social distancing & 34 & 17.6 \\
\hline Safer interactions with clients* & 20 & 10.5 \\
\hline Other & 2 & \\
\hline \multicolumn{3}{|l|}{ Concerned to get COVID-19 } \\
\hline Very concerned & 43 & 22.3 \\
\hline Somewhat concerned & 59 & 30.6 \\
\hline Not concerned at all & 91 & 47.2 \\
\hline COVID-19 state of emergency affected ability to get any needed healthcare & 160 & 82.9 \\
\hline \multicolumn{3}{|l|}{ COVID-19 state of emergency affected ability to get PrEP medication from the study when need it } \\
\hline No & 176 & 91.2 \\
\hline Yes & 17 & 8.8 \\
\hline Difficulty in travelling to pick up PrEP & 9 & 52.9 \\
\hline Moved out of Kisumu & 5 & 29.4 \\
\hline Had other priorities & 1 & 5.9 \\
\hline Other & 6 & 35.3 \\
\hline \multicolumn{3}{|l|}{ COVID-19 state of emergency affected how people treat you because you are a sex worker } \\
\hline Increase in stigma/discrimination & 33 & 17.1 \\
\hline Decrease in stigma/discrimination & 13 & 6.7 \\
\hline No change in stigma/discrimination & 147 & 76.2 \\
\hline Experienced any violence from a client or a regular/main non-paying partner during the COVID-19 pandemic & 28 & 14.5 \\
\hline COVID-19 state of emergency in Kenya affected your income and access to basic needs like food & 178 & 92.2 \\
\hline \multicolumn{3}{|l|}{ COVID-19 state of emergency affected the amount of money you charge to clients } \\
\hline Decrease in payment & 153 & 79.3 \\
\hline Increase in payment & 8 & 4.1 \\
\hline No change in payment & 32 & 16.6 \\
\hline \multicolumn{3}{|l|}{ COVID-19 pandemic affected work with paid sexual partners or clients in any way } \\
\hline Decrease in number of clients & 162 & 83.9 \\
\hline Decrease in interactions with clients & 64 & 33.2 \\
\hline Meeting location has changed & 140 & 72.5 \\
\hline Sex location has changed & 141 & 73.1 \\
\hline
\end{tabular}

*Safer interactions with clients include avoiding kissing, not accepting clients who are coughing or sneezing, wearing a mask, asking clients to wash their hands or use hand sanitizer before having sex, not shaking hands, where meeting or having sex with clients

indicating that violence has spiked since the COVID-19 lockdown in Kenya and elsewhere [17, 18]. Female sex workers are vulnerable to violence from clients as well as from police and community members $[15,18]$. The Kenya Sex Workers Alliance (KESWA) documented 80 incidents of violence against sex workers by clients, neighbors and police in the first month of the pandemic who blamed them as a reservoir of SARS-CoV-2, compared to a monthly average of 25 incidents before the pandemic [18]. This underscores the importance of linking sex workers with anti-violence services and ensuring that those services remain accessible during public health emergencies like the current pandemic.

The IPrEP study procedures were successfully and rapidly modified in the context of COVID-19 to allow for physical distancing while ensuring uninterrupted, safe use of PrEP. Of note, study participants did not experience disrupted access to health care and PrEP specifically, as reported in 
other settings [19-21], due to special measures taken by the study investigators, e.g., distribution of HIVST kits and remote interviewing, put in place to minimize the impact of COVID-19 restrictions on access to healthcare.

Our study findings confirm anecdotal reports of the deleterious effects of COVID-19 on the economic livelihood of sex workers [22]. They are consistent with reports from the Bar Hostess Empowerment and Support Programme in Nairobi, which reported that sex workers have faced a $75 \%$ reduction in payments for sex work in that city since the onset of the pandemic [23]. Job losses in the formal and informal sectors in the western region around Kisumu have coincided with natural disasters in 2020, including massive flooding and a historic locust infestation [24, 25]. This confluence especially impacts sex workers and other vulnerable populations who lack safety nets to cushion loss of existing income sources. Sex workers have demanded that the Kenyan government include them in economic relief initiatives. To help sex workers in Kenya, KESWA launched a fundraising campaign to purchase hygiene packs with hand sanitizer, masks, and menstrual pads as well as food baskets for sex workers, and also is disseminating security tips on how to reduce the risk of violent encounters with clients $[18,26]$. These efforts build on established systems of mutual assistance among female sex workers in Kenya such as chamas (informal savings and loaning groups) and other collaborative activities. Our qualitative research with 30 female sex workers in Kisumu, Kenya, conducted prior to the COVID19 pandemic, found that economic assistance during illness and for funeral expenses and release after arrests were common, as were other forms of support, including protection from violence by clients and the police, social support, and information-sharing [27]. Research into the role of mutual aid practices and networks among female sex workers during the pandemic may yield insight to strengthen interventions that leverage female sex workers' support systems [28-30].

\section{Study Strengths and Limitations}

This study has a number of strengths. To our knowledge, it is one of the few studies that have examined the effect of the COVID-19 pandemic on the lives of young female sex workers in sub-Saharan Africa. It was conducted among a prospective cohort of female sex workers that will be followed for 24 months and will permit us to identify changes in the socioeconomic effects of COVID-19 restrictions over time. The study successfully transitioned to remote interviewing, resulting in an analysis sample $(96.5 \% ; n=193 / 200)$ representative of our complete study cohort. We documented a smooth transition from in-person to remote follow-up with the introduction of HIVST and remote reporting of test results to minimize disruptions to study participation and enable continued access to PrEP medication refills while maintaining social distancing practices at the study site. The study also has several limitations. It assesses the experience of female sex workers enrolled in a PrEP trial, and findings may not be generalizable to other young female sex workers in Kenya. Because questions were interviewer-administered, responses may reflect social desirability and response bias due to reactivity of interviewing participants at regular intervals. COVID-19-specific questions were positioned within the temporal framework of the pandemic-related lockdown and were answered at either the 3- or 6-month follow-up visit, depending on when participants had enrolled in the study. Thus, we were unable to make direct comparisons with baseline responses about experiences of violence, stigma, and discrimination in the past three months. Finally, questions about the pandemic were limited in scope and do not permit a comprehensive assessment of the effects of the COVID-19 pandemic.

\section{Conclusion}

In conclusion, our study confirms the negative impact of the COVID-19 pandemic on a group of young female sex workers in Kenya. These impacts are most keenly felt in reduced financial income, which impacts their livelihood and survival; gender-based violence; and further stigmatization of an already marginalized population. Alternative support and economic relief may be needed as a safety-net measure at this time. Further monitoring is needed to ascertain the intermediate and long-term impact of the COVID-19 pandemic on the livelihood and mental health of this vulnerable population.

Acknowledgements We appreciate the contributions of IPrEP study participants for their time and sharing their perspectives on the impact of the COVID-19 pandemic on their lives.

Authors Contributions All authors made substantial contributions to the conception or design of the work; or the acquisition, analysis, or interpretation of data. JEM, JF, ML. WES, and KA drafted the work or revised it critically for important intellectual content; YW conducted the statistical analysis, and all authors approved the version to be published and agree to be accountable for all aspects of the work in ensuring that questions related to the accuracy or integrity of any part of the work are appropriately investigated and resolved.

Funding NIMH 5R01MH110051; P30 MH43520.

Data Availability Data will be available on request from the Corresponding Author.

\section{Compliance with Ethical Standards}

Conflicts of interest None of the authors have financial or non-financial conflicts of interest regarding funding or ethics. The research was not conducted with animals. 
Ethical Approval This research was approved by the Institutional Review Board of Columbia University Irving Medical Center, NY NY, USA, and the Maseno University Ethics Review Committee, Kisumu, Kenya.

Consent to Participate All study participants completed written informed consent.

Consent for Publication All study participants completed written informed consent. All published data are de-identified.

\section{References}

1. Joint statement by ILO, IFAD and WHO. Impact of COVID-19 on people's livelihoods, their health and our food systems. October 13, 2020. https://www.who.int/news/item/13-10-2020-impact-ofcovid-19-on-people's-livelihoods-their-health-and-our-food-syste ms Accessed: November 23, 2020.

2. OECD. OECD Economic Outlook, Interim Report September 2020. doi:https://doi.org/https://doi.org/10.1787/34ffc900-en. Accessed: November 23, 2020.

3. Rohwerder B. Social impacts and responses related to COVID19 in low- and middle-income countries. K4D Emerging Issues Report 35. Brighton, UK: Institute of Development Studies. 2020.

4. Laiboni N. Kenya's philanthropic tradition tackles the COVID-19 challenge. Chatham House. https://www.chathamhouse.org/exper t/comment/kenya-s-philanthropic-tradition-tackles-covid-19-chall enge. Accessed: November 23, 2020.

5. Samandari T. Responding to Kenya's COVID-19 pandemic whilst preserving progress against HIV. HIV Center for Clinical and Behavioral Studies, Grand Rounds, November 19, 2020. https://www.hivce nternyc.org/hiv-center-rounds. Accessed: December 8, 2020.

6. Kenya's COVID-19 Tracker. https://www.coronatracker.com/ country/kenya/. Accessed: December 22, 2020.

7. https://www.world ometers.info/coronavirus/\#countries/. Accessed: December 22, 2020.

8. Mikwa E. Kisumu: the true reflection of development agenda CS Kagwe. August 10, 2020. https://www.kisumu.go.ke/kisum u-the-true-reflection-of-development-agenda-cs-kagwe. Accessed: November 23, 2020.

9. Mikwa E. Kisumu marks handwashing day a midst Covid 19 pandemic. October 15, 2020. https://www.kisumu.go.ke/ kisumu-marks-handwashing-day-a-midst-covid-19-pandemic/. Accessed: November 23, 2020.

10. Wafula C, Wesonga D. Covid-19: Reagents shortage hits Kisumu testing centre. Nation July 29, 2020 https://www.allafricacom/ stories/202007300193html Accessed: November 23, 2020.

11. Standard Team. Covid testing scaled down as counties run out of reagents. November 6, 2020 https://www.standardmedia.co.ke/ health/article/2001392861/covid-testing-scaled-down-as-count ies-run-out-of-reagents. Accessed: November 23, 2020.

12. Kisia A. 'Unable to deliver': Kemri can only test 4,000 virus samples daily. November 28 2020. https://www.the-star.co.ke/ news/2020-11-28-unable-to-deliver-kemri-can-only-test-4000virus-samples-daily/ Accessed: December 10, 2020.

13. Hawken M. Personal communication from Dr. Mark Hawken, ICAP Country Director via data provided by the Kenya Medical Research Institute - Walter Reed Project, Kisumu and Kenya Medical Research Institute, Kisumu CDC HIV Lab. November 16,2020

14. OraQuick In-Home HIV Test. Package Insert, updated July 3 2012. https://www.fda.gov/media/83607/download. Accessed: November 23, 2020.
15. Ohaga O. Sex workers face a dilemma: to work or not during COVID-19. August 18, 2020. https://africanargument s.org/2020/08/18/sex-workers-face-a-dilemma-to-work-or-notduring-covid-19/. Accessed: November 23, 2020.

16. Amnesty International. Include sex workers in the COVID-19 responses. Index number: POL 30/2788/2020. 28 July $2020 \mathrm{https}$ ://www.amnesty.org/download/Documents/POL3027882020EN GLISH.pdf. Accessed: November 23, 2020.

17. Bradbury-Jones $\mathrm{C}$, Isham L. The pandemic paradox: The consequences of COVID-19 on domestic violence. J Clin Nurs. 2020;29(13-14):2047-9.

18. Bhalla N. 'Hunger or murder': Lockdown poverty exposes African sex workers to more violence. 4 June 2020. Thomson Reuters Foundation. https://news.trust.org/item/20200604011704-4gk53 /. Accessed: November 23, 2020

19. Gichuna S, Hassan R, Sanders T, Campbell R, Mutonyi M, Mwangi P. Access to Healthcare in a time of COVID-19 Sex Workers in Crisis in Nairobi. Kenya Glob Public Health. 2020;15(10):1430-42.

20. Howard S. Covid-19: Health needs of sex workers are being sidelined, warn agencies. BMJ. 2020;369:m1867.

21. Santos GM, Ackerman B, Rao A, Wallach S, Ayala G, Lamontage E, et al. Economic, Mental Health, HIV Prevention and HIV Treatment Impacts of COVID-19 and the COVID-19 Response on a Global Sample of Cisgender Gay Men and Other Men Who Have Sex with Men. AIDS Behav. 2020. https://doi.org/10.1007/ s10461-020-02969-0.

22. Macharia P, Moore S, Mathenge J, Ndunda E, Lazarus L, McKinnon LR, et al. Sexual health among Kenyan male sex workers in a time of COVID-19. Health Education Journal. 2020. https://doi. org/10.1177/0017896920950774.

23. The Global Fund. Sex Workers in Africa Are More Vulnerable During COVID-19 June 4, 2020 https://www.theglobalfund.org/ en/blog/2020-06-04-sex-workers-in-africa-are-more-vulnerable -during-covid-19/. Accessed: November 23, 2020.

24. Development Initiatives. Socioeconomic impacts of Covid-19 in Kenya. Background paper. https://www.devinit.org/resources/ socioeconomic-impacts-covid-19-kenya/. June 2020.

25. Gilliland HC. Gigantic new locust swarms hit East Africa https ://www.nationalgeographic.com/animals/2020/05/gigantic-locus t-swarms-hit-east-africa/\# National Geographic, 12 May 2020. Accessed: November 23, 2020.

26. Mbugua M. Sh49,000 to help sex workers buy food, pay rent, legal fees during pandemic. The Star. 6 July 2020 https://www.the-star. co.ke/news/2020-07-05-sh49000-to-help-sex-workers-buy-foodpay-rent-legal-fees-during-pandemic/. Accessed: November 23, 2020.

27. ICAP at Columbia University. Impact Research and Development Organization. IPrEP Study: Unpublished data; 2017.

28. Halli SS, Ramesh BM, O’Neil J, Moses S, Blanchard JF. The role of collectives in STI and HIV/AIDS prevention among female sex workers in Karnataka. India AIDS Care. 2006;18(7):739-49.

29. Kerrigan D, Kennedy CE, Morgan-Thomas R, Reza-Paul S, Mwangi P, Win KT, et al. A community empowerment approach to the HIV response among sex workers: effectiveness, challenges, and considerations for implementation and scale-up. Lancet. 2015;385(9963):172-85.

30. Reza-Paul S, Steen R, Maiya R, Lorway R, Wi TE, Wheeler T, et al. Sex Worker Community-led Interventions Interrupt Sexually Transmitted Infection/Human Immunodeficiency Virus Transmission and Improve Human Immunodeficiency Virus Cascade Outcomes: A Program Review from South India. Sex Transm Dis. 2019;46(8):556-62.

Publisher's Note Springer Nature remains neutral with regard to jurisdictional claims in published maps and institutional affiliations. 